Please do not remove this page

RMIT

UNIVERSITY

\title{
Qualitative inequality: experiences of women in Ethiopian higher education
}

Molla, Tebeje; Cuthbert, Denise

https://researchrepository.rmit.edu.au/esploro/outputs/9921862408001341/filesAndLinks?institution=61RMIT_INST\&index=null

Molla, T., \& Cuthbert, D. (2014). Qualitative inequality: experiences of women in Ethiopian higher education. Gender and Education, 26(7), 759-775. https://doi.org/10.1080/09540253.2014.970614

Document Version: Accepted Manuscript

Published Version: https://doi.org/10.1080/09540253.2014.970614

Repository homepage: https://researchrepository.rmit.edu.au

(C) 2014 Taylor \& Francis

Downloaded On 2023/04/26 22:33:41 +1000

Please do not remove this page 
Thank you for downloading this document from the RMIT Research Repository.

The RMIT Research Repository is an open access database showcasing the research outputs of RMIT University researchers.

RMIT Research Repository: http://researchbank.rmit.edu.au/

\section{Citation:}

Molla, T and Cuthbert, D 2014, 'Qualitative inequality: experiences of women in Ethiopian higher education', Gender and Education, vol. 26, no. 7, pp. 759-779.

See this record in the RMIT Research Repository at:

https://researchbank.rmit.edu.au/view/rmit:28423

Version: Accepted Manuscript

Copyright Statement: (c) 2014 Taylor \& Francis

Link to Published Version:

http://dx.doi.org/10.1080/09540253.2014.970614 


\title{
Qualitative Inequality: Experiences of Women in Ethiopian Higher Education
}

\author{
Tebeje Molla ${ }^{1}$ \& Denise Cuthbert ${ }^{2}$ \\ ${ }^{1}$ Centre for Research in Educational Futures and Innovation, Deakin University, 221 Burwood \\ Highway, Victoria 3125, Melbourne, Australia \\ ${ }^{2}$ School of Graduate Research, RMIT University, VIC 3001, Melbourne, Australia
}

\begin{abstract}
This article examines the lived experiences of women in Ethiopian higher education as a counterpoint to understandings of gender equity informed only by data on admission, progression and completions rates. Drawing on a critical qualitative inquiry approach, we analyse and interpret data drawn from focus group discussions with female students and academic women in two public universities in Ethiopia. Individual accounts and shared experiences of women in higher education revealed that despite affirmative action policies that slightly benefit females at entry point, gender inequality persists in qualitative forms. Prejudice against women and sexual violence are highlighted as key expressions of qualitative gender inequalities in the two universities. It is argued that higher education institutions in Ethiopia are male-dominated, hierarchical and hostile to women. Furthermore, taken-for-granted gender assumptions and beliefs at institutional, social relational and individual levels operate to make women conform to structures of disadvantage and in effect sustain repressive gender relations.
\end{abstract}

Keywords: Ethiopia, gender, higher education, lived experience, qualitative inequality

\section{Introduction}

In Ethiopia, due mainly to the extensive expansion of the higher education (HE) system coupled with the effect of equity policies and strategies (FDRE, 2009; MoE, 2004; TGE, 1994), the representation of women in public universities has steadily increased since the early 2000s. In the 1986/87 academic year, the number of female students in post-secondary education accounted for only 7\% of the total enrolment (UNESCO, 1988); and in 1998/99, the proportion of academic women in public HEIs was merely 6\% (Wondimu, 2003). These numbers have gradually improved since then to reach $28 \%$ and $9.5 \%$ for female students and academic staff respectively in 2011/2012 (MoE, 2013). Even so, two decades since the introduction of preferential admission policies for socially and historically disadvantaged groups, inequality in access to and success in HE remains a serious challenge.

More importantly, what is missing from government policy reports and statistical summaries are the qualitative aspects of the problem of gender inequality in HE which persists in the face of the increased participation of women in Ethiopian HE. While non-discriminatory (or equal) access to HE may be considered a good starting point for policy, given the structural 
impediments (including the intersection of the gender order, poverty and disadvantaged ethnic background), the educational and working experience of women within the HEIs deserves policy attention at least equal to that given to participation rates.

The gender order of higher education institutions (HEIs) - as expressed in power relations, division of labour, and cultural beliefs and stereotypes (Connell, 2009; Ridgeway, 2011; West \& Zimmerman, 1987, 2009) - shapes the experience of men and women differently. Gendered power relations, that operate at micro- and macro-levels, are pivotal to the position, progress and experiences of women. Yet, most often, international and national gender equality initiatives in $\mathrm{HE}$ employ indicators related to the number of female staff and students rather than qualitative indicators of women's gendered experiences in the educational setting (Arnot \& Fennell, 2008). By focusing exclusively on indicators of quantitative inequalities, higher education policy actors in Africa overlook institutionally-embedded disabling constraints that (re)produce the problem of gender inequality (Mama, 2003; Mama \& Barnes, 2007). In this paper, we address this limitation. The present study is a contribution toward understanding the gendered experiences of women in Ethiopian HEIs. It highlights qualitative indicators of the persistence of inequality as expressed by women themselves whose experiences encompass harassment, sexual violence, persistent discrimination, prejudicial treatment, poor results, minimal career advancement and covert and overt hostility to their participation in HE. As we argue below, women in Ethiopian HE are profoundly "misrecognised" and come to internalise this, risking the misrecognition of themselves as valid actors in this space.

The discussion is divided into four major sections. The first section presents a theoretical overview of social relations and structural inequality. The second section briefly discusses relational analysis of experience as a methodological approach employed in the study. The third section presents the key findings of the study - specific expressions of qualitative gender inequality, namely prejudice and sexual violence. Lastly, the section on women's conformity to structures of disadvantage highlights why some women in HE tend to see the state of inequality as a normal condition.

\section{Theoretical Overview}

We see gender in social relational terms - as a social practice that frames relations between the sexes on an unequal basis (Krais, 1993; McNay, 2008; Ridgeway, 2011; Risman, 2004). The social relational approach to the study of gender inequality in education recognises the 
importance of both the subjective view of experiences and beliefs, and the objective explanation of social action in terms of material and cultural structures. It enables us to see the social reality as a 'set of invisible relations' (Bourdieu, 1990), explicate the recursive relationship between individual agency and structures, and explore differentiated power relations in the social space.

The social relational understanding of gender brings to the fore experience, structures and agency as valid areas of inquiry. Experience encompasses what has happens to individuals in temporal and socio-spatial contexts, and its impact on them. It is a lived phenomenon. In the words of Lois McNay (2008), experience is the "living-through of embodied tendencies [or dispositions]” (p.182). Importantly, subjective experiences are expressions of the positioned interactions of agents in a system of social structures. Hence, the process and contents of lived experiences and meanings agents attribute to them shed light on the dynamics of the social space - the social structures and individual agency. Here social structures refer to relatively enduring and recognizable patterns of relationships expressed in the form of networks of relations, and the norms and values that define those relations (Connell, 2009; West \& Fenstermaker, 1995; Young, 1990). Social structures can take two broad forms: a) cultural values and norms that define patterns of social relations and practices, and b) systemic arrangements (e.g. rules, regulations and policies) that determine rights and duties of members of a social group. As such, social structures can be enabling or constraining factors that determine our opportunities, choices and actions.

However, individuals and groups do not always passively conform to structural impositions and expectations. Experience-centred accounts of gender relations, for example, provide insights into the structures of imposition women face but also the forms of agency expressed in an act of resistance to an undesirable condition of existence. Agency refers to individual's freedom to be and do what s/he values in life. It is the ability to make choices, resist repression and act on impeding structures. Therefore, in studying lived experiences, accounts of agency should include both "ways in which actors are caught within structures of power and domination" and "their capacity for practical reflection" (McNay, 2008, p.183). As it is evident in the success of a few academic women in Ethiopian universities, people resist and manage to overcome challenges and impediments. However, it is also important to note that agency goals are reflections of conditioned aspirations and their fulfillment may not necessarily indicate the absence of structural constraints. 
Whereas individuals may have choice and agency, they are often subjects of constraints associated with cultural expectations and institutional practices. Individuals or groups are in a state of structural inequality when their access to resources and opportunities, and the possibilities to exercise their agency, are constrained due to their gender, ethnic background, religion or socio-economic positions in society. As Risman (2004, p.432) rightly notes, "[t]he social structure as the context of daily life creates action indirectly by shaping actors' perceptions of their interests and directly by constraining choice” (emphasis added). In other words, structural or systemic causes of inequality are entrenched "in unquestioned norms, habits, and symbols, in the assumptions underlying institutional rules and the collective consequences of following those rules” (Young, 1990, p.41). In explaining constraining effects of social structures, Young (2000), using Marilyn Frye’s (1983) birdcage metaphor, writes:

The cage makes the bird entirely unfree to fly. If one studies the causes of this imprisonment by looking at one wire at a time, however, it appears puzzling. How does a wire only a couple of centimetres wide prevent a bird's flight? One wire at a time, we can neither describe nor explain the inhibition of the bird's flight. Only a large number of wires arranged in a specific way and connected to one another to enclose the bird and reinforce one another's rigidity can explain why the bird is unable to fly freely (Young, 2000, pp.92-93).

Like the wires of the cage, social structures interconnect to limit opportunities and shape actions of individuals in the given institution or society to produce structural, durable inequalities. As Bourdieu (1990), Krais (1993) and Risman (2004) remind us, even our mental structure through which we discern the social reality around us has been formed through an internalization of the social structures we encounter since the early stage of our lives.

Gender-based analysis of social structures shows that sex difference is not a problem per se. The problem arises when difference fails to entail a different-but-equal relationship between female and male persons. Traditionally, gender difference has been defined in ways that imply hierarchy, presupposing the superiority of men in relation to women as "masculine pursuits are given greater value” (Deutsch, 2007, p.117). When allocation of power and resources is aligned with the gender category, the difference readily transforms into inequality. Conversely, the persistence of inequality is founded on the act of maintaining gender difference as a natural, and hence acceptable, condition. 
When it comes to structural gender inequalities in education, two issues are worth noting. First, structural inequalities are drawn on 'mutually sustaining schemas' that deprive opportunities and constrain agency (Sewell, 1992). That is, structures shape people's practices, and such practices in turn reproduce the structures. Gender influences women's practices and choices and is a key structuring element. Gender defines inequalities in resources and opportunities, respect and recognition, and domination and exclusion. Further compounding these effects, women may contribute to sustaining the social structures that oppress them through their conformity, whether willingly or otherwise, to the existing roles, norms, expectations in their daily practices and interactions. Structural (categorical) inequalities extend from one context to another along the defined category (social grouping) such as men/women. As sociologist Charles Tilly observes: "the routines, understandings, and justifications that organizational participants have acquired in other settings are readily available for organizational work” (1998, p.58). In this regard, power relations, beliefs, assumptions, and practices shaping the interaction of men and women in the classroom and at the workplace are closely linked to the broader gender cultural beliefs of the society.

In this study, we aim to understand women's experiences and subjective representations of their interactions with objective structures through a close analysis of the accounts of lived experiences of female students and staff in selected public universities in Ethiopia.

\section{Methodology}

To produce a body of knowledge that exposes 'hidden structures' of inequality and potentially provides insights to transform repressive relationships, it is important to assume a 'critical gaze' on social arrangements and discursive practices. The primary intention of critical inquiry is reflectively to illuminate "structures of oppression as they operate in the worlds of lived experience” (Denzin, 1994, p.509). Human beings have a natural inclination to understand and make meaning out of their lives and experiences. Specifically, because of their structurally oppressed position in relation to their male counterparts, women have a "nuanced understanding of social reality" and their lived experiences can serve as a valid site of knowledge construction (Hesse-Biber, 2012, p.11).

For this study, we syndicate the 'critical gaze' with what Lois McNay (2004, 2008) refers to, based on Bourdieu's (1990) idea of the 'phenomenology of social space', as a relational analysis of experience. As a reflexive approach to exploring social reality, a critical relational 
analysis of experience is instrumental in illuminating embodied dispositions of agents, material and social structures of deprivation, individual agency, historical constitution of the relations, and expressions of 'misrecognition'. It places experiences of agents (as captured through their reflexive accounts) at the core the analysis of social interactions and power relation in the field. A relational analysis of lived experiences of individuals and groups "attempts to situate experience within the complex set of symbolic and material relations that explicitly and implicitly structure it” (McNay, 2008, p.138). A gender-based relational analysis of experiences is vital to understand social and cultural reproduction of gender inequality. It enables us to understand women's accounts of their lived experiences in relation to their social positions. As Bourdieu (1990) rightly notes, “The dispositions acquired in the position occupied imply an adjustment to this position” (p.128). Associated with this, the relational approach gives us access to embodied dispositions of women which, in turn, helps to problematize the role of internalized social structures in women's disposition to misrecognise the conditions of their subordination.

Understanding gendered experiences in social relational terms implies that women apprehend the social world as 'the reality of their daily life' through commonsense constructions and interpretations of their experiences in it. Therefore, a sound approach to scientific knowledge construction of their lived experience should draw on women's self-reflective commonsense accounts (Bourdieu, 1990). That is, lived experience is studied as it reveals itself to us through narratives. This approach requires a critical examination of social contexts in which the experience is enacted to elicit rich data on the question of what is it like to be women in Ethiopian HE system? Researching the relationship between lived experiences and their social contexts focuses on both describing the experiences and understanding the "meaning of the expressions” of the experiences (van Manen, 1997, p.27). Exploring lived-experiences of structural inequality in higher education, for example, rests on a phenomenological assumption that experiences can become part of consciousness and be available for description; and that the analysis offers insights into structures of repression, individual agency, and agents’ interpretations of their experiences.

Although a critical examination of lived experiences brings to light the impact of structural factors on the lives of women in patriarchal societies and expressions of their agency, we acknowledge that the subjective realm that privileges their narrative accounts as a source of scientific knowledge is contentious (McNay, 2004, 2008). Accounts of lived experiences do not fully capture representations of the social reality. This is partly related to the routineness 
of much of our social life and our tendency to take it for granted (Risman, 2004). The inaccessibility of some aspects and meanings of human experiences is also linked with the latent or invisible nature of social structures. As Bourdieu (1990) underscores, "the truth of any interaction is never entirely to be found within the interaction as it avails itself for observation" because "the visible, that which is immediately given, hides the invisible which determines it” (Bourdieu, 1990:126-7). Hence, we are conscious that it is hardly possible to fully attend, through accounts of practices, to social and historical factors that produce individuals’ positions, experiences and meanings in the social space.

The research reported here forms part of a larger study on the problem of inequality in Ethiopian HE. The data analysed and discussed in this article were collected during focus groups discussions (FGDs) conducted in 2010. The discussions were used as dialogical instruments to generate the required qualitative data. Four sets of discussions were conducted with two groups of female students and two groups of academic women in two public universities in Ethiopia. There were five participants in each group. The semi-structured guiding questions developed for the discussions concentrated on women's gender-related experiences in their respective institutions. Each group discussion session lasted for about an hour. In order to access a range of views and experiences, the groups were made as diverse as possible - in terms of participants' academic positions, fields of study, and years of service. The wide range and purposeful selection of discussants enabled us to draw patterns (similarities and/or differences) among different subsets within the FGDs, based on common and different characteristics defined for each group. In analysing the data, we applied intragroup thematic analysis and inter-group comparison (Kamberelis \& Dimitriadis, 2008). The thematic analysis enabled us to identify and explain shared experiences and to capture differences across topics of discussions within the groups. The inter-group analysis was imperative to uncover the contours of gendered experiences across the terrains of different organizational settings and histories where women work and learn.

We have selected accounts from the data to illustrate the ways in which women described their experiences of their universities. These accounts are clearly subjective and limited. However, we believe that the consistency of such account provides evidence of qualitative gendered experiences of female students and academics in Ethiopian HE. 


\section{Gendered Experiences of Women in Ethiopian HE}

We become gendered when we believe that "men and women are different and unequal, that the inequality comes from those differences, and that, therefore, such inequality is justified" (Kimmel, 2008, p.176). In a society where patriarchy operates as an ideology, boys, unlike girls, may enjoy an optimistic social environment which is predisposed towards their success and independence in life endeavours. An asymmetric gender-based division of labour confines women (and girls) largely to the domestic sphere and also influences and constrains their educational and career aspirations. In Ethiopia, notwithstanding the fact that values accorded to women differ from one ethnic group to another, the general pattern is that feminine traits are less appreciated than masculine ones (Levine, 1999; Molla, 2013).

Qualitative indicators of inequality in education are closely linked with structural factors which are deeply rooted in the organization and functioning of society; and operate within such key social categories as gender, class, ethnicity, and rurality. Therefore, numerical representations such as rates of enrolment, progress and completion are simplistic in the sense that they are a one-dimensional expression of the problem and do not adequately capture the underlying factors of inequality or the experience of inequality. Even when women manage to continue their study, they still face the patriarchal power relations and biased cultural beliefs expressed through such gender-based structural inequalities as under-representation in decision-making, deprivation of respect and recognition (including prejudice, and exclusion or misrepresentation of women's roles and contributions in the curricula), and sexual violence.

Without a proper understanding of the structural factors of disadvantage that result in qualitative inequalities, it may not even be possible fully to grasp the quantitative aspect of the problem such as the continuing under-representation of women in HEIs. For example, while male academics benefit from the freedom from household burdens to widen their professional networks within and outside the university, and get their work published, most women face extreme challenges in advancing in their careers in the face of the impediments within and outside their workplace. Academic advancement requires extended studies in adult life and absences from work and family. Childrearing and parental leave, coupled with disadvantages leading to limited educational attainments, make it difficult for women in Ethiopia to fulfil such requirements as doctoral degrees and the scientific publications necessary to assume senior positions and earn professorships. The majority of female staff in the two universities do not hold PhDs and are concentrated in the lower academic ranks. They 
have lower incomes than their male counterparts who have higher positions and better qualifications to attract research funds and other rewards. At WU, as shown in Figure 1, the representation of women drastically declines as the level moves from undergraduate study to full professorship.

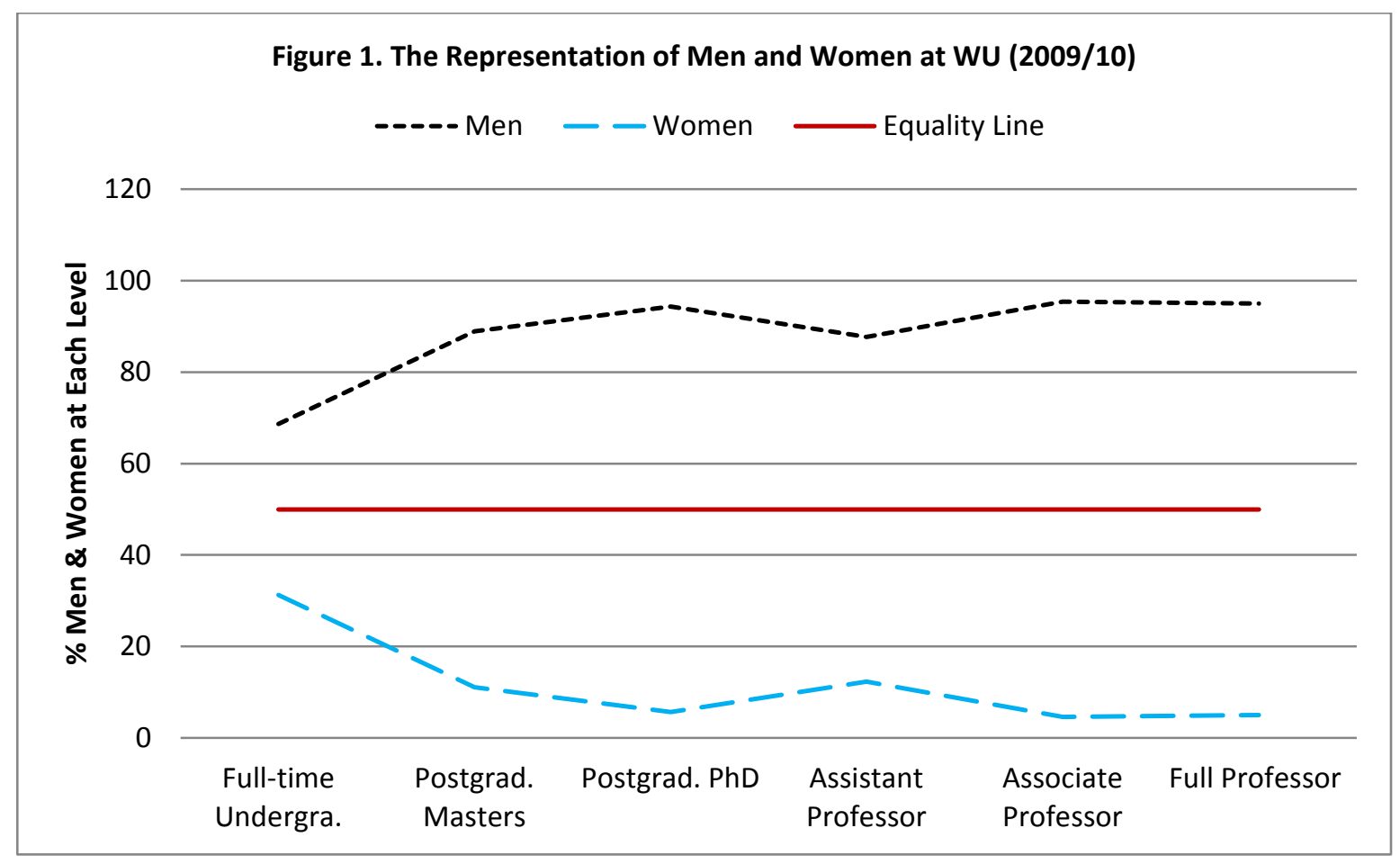

Source: Computed based on data from Human Resource Management Statistical Report of the university; and Education Statistics Annual Abstract (MoE, 2011).

In this section, we explore individual and shared meanings and experiences of women in relation to key gender-related changes in their respective institutions by drawing on focus group discussions with women in two public universities in Ethiopia. Gendered experiences of the female staff and students who participated in the focus group discussions are organised in two major themes: prejudice and sexual violence. We found that while many of the women shared common experiences and had common responses to these, there was significant diversity in their reports. Female students specially highlighted the hostile learning environment as a key concern while academic women tended to underscore lack of recognition and disempowerment. We use pseudonyms for the two public universities as well as in reporting accounts of individual participants in the FGDs. 


\section{Prejudice}

Stereotyping mainly involves attributing specific negative or positive characteristics to individuals by reasons of their membership of a particular group or class. Flowing from negative stereotyping, prejudice is broadly defined as "the process of categorization (generalization) and subsequent indiscriminate dislike or animosity toward the relevant category and its members” (Bodenhausen \& Richeson, 2010, p.342). According to social psychologists Robert Baron and Donn Byrne, people hold irrational negative views (prejudice) toward a social group because this prejudice allows them to bolster their own self-image (to feel superior) in a real or imagined competition between groups over valued opportunities (e.g., high status and power); and/or because they are socialised to view a particular group unfavourably (Baron \& Byrne, 2003). The consequences of prejudicial attitudes may range from mistreatment and discrimination to dehumanization and persecution of members of the targeted group.

From a categorical/structural inequality perspective, prejudice towards a social group is a key instrument of marginalization and subordination, and is enacted in social interactions and communications. As an ideology of oppression that universalises the experiences, norms and expectations of men, patriarchy involves what Young refers to as cultural imperialism, by which the culturally dominated "are both marked out by stereotypes and at the same time rendered invisible” (1990, p.59). A negative stereotype is an expression of cultural domination and underlies durable inequality: it works to delimit the dominated "to a nature which is often attached in some way to their bodies, and which thus cannot easily be denied" (Young, 1990, p.59).

The accounts of the lived experiences of academic women and female students in Ethiopia show how gendered expectations operate in learning and working contexts. Even in the policy climate of equal opportunity as exists in Ethiopian HE, the narratives of women in the two public universities reveal how little impact the policy regime has on the deeply gender-biased culture at work in these institutions in which men engage in both overt mistreatment and subtle marginalization of female students and colleagues with apparent impunity. A graduating-class female student at OU, Oded, recollected her experience of prejudice as a first-year student:

It was the end of the semester [...] I was shocked and devastated to see a really bad grade in a course. I went to the lecturer's office and asked him to 
let me see my paper. Then another teacher came in and interrupted our discussion. He soon started joking on me. They did not see me as one of their students who came to check a result but rather as a female, possibly lazy student, who sought a favour in an exchange for a sexual offer. [...] He asked me: 'Do you think you can score better than you already have?' and continued laughing. They continued making mockery out of me, a female not accepting a low grade. I was [..] devastated by the way they treated me and left their office to cry. I hate myself. [They] made me a victim over there. It has been a terrible experience. From that moment onwards, I never visit my teachers in their offices (FGD, 02 October 2010).

This gendered stereotyping and devaluation result in Oded internalising the dominant view that she is unworthy of her place at university and a disabling misrecognition of her validity as a student: “I hate myself”. Confirming Miller and Miller's supposition that 'faculty transmit values and beliefs about the world and expectations about students' potential places in that world” (2002, p. 106), after this experience, Oded strictly limits her contact with teaching staff. The effects of prejudice and exclusion are thus perpetuated through her own actions, to her cost as she is deprived of "beneficial out-of-class interactions" which "acculturate students in the values and norms of academic and professional communities" (Miller and Miller, 2002, p. 106).

As discussants at OU emphasized, when female students perform well academically, their male peers resist accepting this as a genuine achievement. Rather, the achievement is attributed it to advantage gained from sexual favours with male teachers. This supports the conclusion that Morley draws from her study on the experience of female students in selected universities in Ghana and Tanzania: “The doxa of sexualized pedagogical relations means that if women fail, this is evidence of lack of academic abilities and preparedness for higher education. If they achieve, this is attributed to women's 'favoured' position in gendered academic markets” (2011, p.113). The operation of this prejudicial attitude deprives women of the confidence, assertiveness, and aspirations needed to succeed. Further, prejudicial attitudes against women and their capacities can also contribute to gendered disciplinary streaming and subsequent 'opportunity [traps]' (Brown, 2003) and stagnant social mobility.

In the case of academic women, their sense of disempowerment is evident in their accounts of the denial of academic recognition and experiences of mistreatment and exclusion. Odhi from OU observed that when male colleagues ask for assistance it is construed as nothing other than a request for help. However, if a woman does that same, a very different construction applies. As she reports, male colleagues shout: “If she can't do it why does she accept the 
responsibility in the first place? It should be taken by someone else who is capable of doing it” (FGD, 23 September 2010). She added:

Gender-biased actions of men colleagues may speak louder than their words. [...] I observe them hesitating to give me certain works to do or to accept what I accomplished as a fruit of my own efforts. Another aspect of our problem is that male students do not show respect to us. They respect male teachers. They mistreat us for merely being women teachers. They do not expect anything worthy from us I think (FGD, 23 September 2010).

This indicates the degree to which male students readily read the gender politics at work in Ethiopian HE, paying female staff less respect than that given to males.

Prejudice and low expectations based on gender within HEIs are expressed through often unspoken but nevertheless important messages about the capacities, contributions and roles of women. According to Wahi, a senior academic woman at WU, the failure to recognise and respect women's academic abilities is strongly associated with the sexist mind-set of male peers:

There would be no meaningful change unless the mind-set of men is changed. They [male academic staff] need to accept the very fact that women are not inferior, in any aspect, to men. They should be convinced that women are capable and equal. [..] They have to appreciate what we have to say. They have to respect the body of knowledge we produce. They have to have confidence to give positions to us. They need to believe in what we can think and do. However, I am so pessimistic that this University would change soon. That is what I have witnessed in my long experience as an academic woman in the institution (FGD, 25 October 2010).

Asked about their participation in decision-making in their Centres/Departments, most of the discussants expressed their experience of unfavourable social relational contexts. At OU, an academic woman, Odawo, shared her scepticism about gender equity-related changes in her university:

Even though I have a short experience as an academic staff here, I have a frustration. We have problems in assuming positions. The male colleagues still have no confidence on what I do and say. Once, the department head told my colleague that she was a lazy teacher. She asked him: 'Why?' His reply was even more annoying. He replied, 'When I think of you, I feel like that'. Given this kind of stereotypes, I do not think that they would give us a chance to assume a position. I am so pessimistic about being equally treated in this university (FGD, 23 September 2010).

The accounts of the lived experiences of academic women in the two universities reveal that structural and cultural factors continue to constrain women's participation in higher level 
decision-making positions. This provides a basis for critique of gender equity policies in Ethiopian HE that tend to focus on personal attributes such as women's under qualification relative to men and their lack of assertiveness. In the absence of pervasive legislative and policy regimes to address the problem within HE institutions, the structural factors of inequality in HEIs function to implicate the real or presumed attributes of women themselves as the reason for their status. That is, women's under-representation in certain ranks or their lack of career progression is held to be due to women's lack of confidence, self-esteem or their lack of qualifications: an understanding of women as deficit is perpetuated. This dynamic works to “confirm patriarchy's self-fulfilling prophecy that women don't have what it takes to stay the course for the long haul" and become "unreliable candidates" for highly sought-after positions (Singh, 2002, p.34). Left unaddressed, this chain of disadvantage develops into (and subtly underlies) disadvantages in distributions of resources and opportunities. Wahi, one of the focus group discussants, cited a recently enacted housing policy of WU as an example:

Let me tell you another systematic injustice when it comes to gender equity [in this University]. When we discuss on the housing policy, we agreed to give a 5 point advantage for women. On the other hand, there is a 20 point advantage for Office holders. It is a common knowledge that most of the Offices in the University are held by men, and hence they still maintain a dominant advantage as a fair share in the housing policy (FGD, 25 October 2010).

Prejudicial attitudes toward women's potential and their contributions are detrimental to the extent that even equity measures such as affirmative action policies are considered to be confirmation of the inferiority of women. As a result, beneficiaries of the equity policies frequently endure hostile abuse and belittling comments from male students and teachers. Unsurprisingly, due to consequent socio-psychological stress many of them fail to succeed. Repeated references to women as less capable and weaker than men may socialize women to accept inequalities as a normal condition and to formulate lower expectations for themselves and for their careers.

\section{Sexual Violence}

Higher education institutions, as part of the society, present a 'social relational context' framed by norms and values that position women in a particular, usually unfavourable, situation. Here the discussion on violence against women is limited to sexual harassment and related problems female students reported in the two universities. 
Sexual harassment is an imposition of unwanted sexual attention, and is intrinsically linked with unequal power relations - it is "a gendered expression of power” (Uggen \& Blackstone, 2004, p.64). Michael Kimmel identifies two broad categories of sexual harassment:

In the most obvious, quid pro quo form, a trade of sexual contact is offered for a reward or the avoidance of punishment. This is the sex-for-grades model of teacher-student interaction [...]

The second is far murkier and is understood as the creation of a 'hostile environment,' one in which women feel compromised, threatened, or unsafe (2008, pp.225-226).

Discussions with women in the two universities disclose that both forms of sexual harassment are prevalent in public universities in Ethiopia. Female students are asked for sex in exchange for good grades from male teachers, and face sexual assault and bullying from their male peers in lecture halls and libraries. There are reported cases of sexual abuse by male teachers and students against female students in the two universities. Odafi is a graduate student at OU. She reported her experience during her undergraduate study:

When I was a third year student, one of the male teachers in the Department asked me for love affairs and I declined to accept because I was not interested to have a boyfriend or get married. I had other priorities. Yet he insisted asking me the same question. One day he called on me to his office and brought my exam papers and warned me: "Here are your answers for the essay questions and the result is in my hand. If you accept my request, you will get 'A' and if you are still not willing to accept you will get ' $F$ ' (a fail)". I was worried. What could I do? If I took the case to the Dean's Office, I knew they would not take any measure to help me. I lost hope. My dream to graduate and get a job was frustrated. [...] I [shared] the issue only [with] one of my closest friends. [...] she advised me to go to his office and tell him that I would do all what he needed after the result was released. I did as I was advised. But he was not convinced and gave me a low grade. I suffered a lot for being a woman and for not accepting his request. I never forget this experience (Odafi, FGD, 02 October 2010).

The same kind of offensive behaviour also comes from their male peers. Odla's experience at OU shows the magnitude of the hostility that female students face. Her story details sexual harassment in the university library:

On one evening I had to prepare for an exam [...] I was reading in the University library at night. At around 2 am this male student came to me and asked what time it was. I told him. He came closer and seated next to me. Then he [moved] his leg and touched my feet. After a while, he tried to physically abuse me. I escaped and went to my dormitory crying. I did not expect this kind of aggressive behaviour in a library. Library was supposed to be a safe place. Sadly, male students do not take this action seriously. 
[They] try to simplify it just an expression of a natural and harmless feeling. This is not true for me. It is a cruel offense one may encounter (Odla, FGD, 02 October 2010).

As the accounts of Odafi and Odla reveal, in the context of repressive gender relations, sexual harassment of female students by male staff and peers may not be considered a serious offense against an individual or a group. Most often, sexual violence is linked with "culturally prescribed expressions of sexuality” (Uggen \& Blackstone, 2004, p.67) that underpin the irrational hidden curriculum that furnishes the mind-set of male students and teachers on campus. As Odafi indicates, the implicit legitimation of sexual harassment of women in the university lead to the view that even a complaint to the Dean is pointless.

The problems faced by these women appear to have been exacerbated by the absence of appropriate guidance and counselling support within the institutions. Fear of revenge, victimization and stigmatization, frequently constrains women from reporting incidents to the university authorities, and this non-reporting allows the abusive culture to continue. Discussants in this study made it clear that, especially when the case involves male teachers, that fear of revenge by the offender and his colleagues is a key reason for silence of victims of sexual harassment in HEIs. Odabe, one of the discussants in the FGD at OU, underscored:

The challenge is that whenever a female student is harassed by her male teacher and complains to the department head, no action is taken. Rather all his friends would take it as an offense against their dignity and seek to avenge the complaint. [...] To be honest, if I were the victim I would prefer to stay silent (02 October 2010).

Women's reluctance to report sexual violence and associated psychological stress is mainly attributable to their sense of disempowerment in the absence of viable institutional structures to respond to such issues. It is clear from the accounts of the discussants that there is both a lack of protection against, and appropriate disciplinary responses to, the sexually hostile encounters they face on campus. Wame, a student in the FGD at WU and a member of the leadership of University's Female Students Association, affirmed that there was a number of harassment cases reported by female students in the 2009/2010 academic year. As she noted, the University is particularly reluctant to take action against male academic staff who are allegedly involved in "sexual corruption” with female students. She continued:

I would like to tell you a case that I know of because of my position as a member of the University's Female Students Association. The case was that a teacher asked his graduating female student for sex. She rejected the request even though she knew that she would suffer from the bad 
consequence from him and his friends in the department. As a result she got 3 Fs [failing grades]. So, she reported to the department, and later to the ministry of Women's Affairs. All her efforts were with no tangible result. She had to spend another year to take the three courses again. She was morally damaged as well (FGD, 21 September 2010).

Wame also explained that hostility to women on campus has more damaging effects on female students from rural areas than on their peers from urban centres. She noted that the university context presents rural female students with a unique and challenging experience, far removed from their cultural values and norms. Their shyness and lack of assertiveness illequip them to deal with sexual harassment in the new environment of the university. A high rate of attrition among this group of students (Andualem \& Gebre-Egziabher, 2009) can partly be ascribed to excessive fear and stress, which eventually put their academic survival in question.

A hostile learning environment as manifest in prevalent sexual harassment has critical repercussions on the progress and success of female students in HE. Most of the female students who took part in the discussions stressed that the library services and dormitory conditions were not favourable to study. At WU, 50 to 60 female students live in a single dormitory, making private study almost impossible. Assignments for major courses require extensive reading, which places the onus on individual students to ensure their own progress and assumes library use as a pre-condition for success. Male students can go to the library anytime they like and do their assignments while their female counterparts face various obstacles to doing so. The day time is occupied by classes with little time to read in the library. At night, there is fear of male students' bullying them on their way to and inside the library. This makes the issue of quiet and safe places for private study critical for female students. Without such conditions, the chances of success for female students remain compromised.

\section{Conformity to Structures of Disadvantage}

As much as social structures influence individual choices and actions, individuals have the capability to act on and transform the structures (Giddens, 1984). This is evident in the success of a few women in Ethiopian HE. However, in most cases, women's agency is significantly inhibited by subtle structural impediments of almost overwhelming proportions with profound impact on women's daily experiences of the university. 
One of the essential features of structural inequality is that it may be overlooked, misunderstood or denied by those most disadvantaged by the inequality. Dominant groups in society propagate the illusion of rationality in the state of inequality and subordination, and most often dominated groups subscribe to the dominant discourse and conform to their condition of disadvantage. This 'shared' misrecognition of the 'logics of practice' in the social space as normal conditions is what Bourdieu (2001) refers to as symbolic violence. He explains:

[Symbolic violence is] instituted through the adherence that the dominated cannot fail to grant to the dominant (and therefore to the domination) when, to shape her thought of him, and herself, or, rather, her thought of her relation with him, she has only cognitive instruments that she shares with him and which, being no more than the embodied form of the relation of domination, cause that relation to appear as natural (Bourdieu, 2001, p.35).

In this scenario, disadvantaged individuals or groups may view their experiences as isolated incidents rather than as part of a categorical deprivation. The tendency not to question deeplyseated structures of repression and injustice is mainly ascribed to ideologies/discourses consciously constructed by dominant groups in society. In a patriarchal ideology, for example, gender-based relations of domination are constructed as neutral so that objects of domination (usually women) take the condition as normal and acceptable.

As is the case in most traditional societies, in Ethiopia, women have been socialized to be polite, compliant and obedient in the family and in the society at large (Worku, 2001). The social relations in HEIs reinforce their conformity to gendered assumptions which contribute to their lack of assertiveness, low self-esteem, and subordinate position. As a result, some of the discussants were found to have internalized gender stereotypes. Odage, an academic woman at OU, observes that women's self-perception conforms to and is shaped by genderbiased attitudes and low expectations towards women. She reflected:

We do not believe that we can do things as efficiently as men can do. I can explain my experience here. The Dean asked me to take some responsibilities (tasks), and I was not confident enough to accept at that time. Rather I told him that I would like to do the task with somebody, and that somebody was my male colleague in the department. This was due to my own lack of confidence in me (FGD, 23 September 2010).

In Ethiopian HE, despite the adverse and subtle structural barriers they face, women's ostensible lack of merit is the ideology that justifies their underrepresentation in senior- and middle-level management positions, and in career development opportunities. This same 
assumed lack of merit relegates the majority of women to disciplines considered to lack the rigour - and hence the longer-term career rewards - in which male students predominate.

Institutionalised social inequalities, as they are embedded in the structures and practices of institutions and persist without the critical consciousness of many participants, tend to reproduce themselves with invisible and 'depersonalized' forms in which dominant group members may not only fail to acknowledge that inequality exists, but are also likely to actively perpetuate their privileged position. Subordinate group members may also see institutionalized inequalities as 'just the way things are'. When it comes to the problem of gender inequality, Morley (2006, p.544) argues that institutional 'micropolitics', that is, the way power is relayed "through seemingly trivial incidents and transactions", makes repressive gender relations in HE difficult to describe definitively. This elusiveness and subtlety occasionally leaves women uncertain about the implications of their social position and the meaning of their experiences.

Furthermore, as the evidence in this study shows, women's conformity to some gender norms and structures of inequality may stem from their lack of trust and pessimism regarding gender-related changes underway in the institutions. A group of discussants at OU stressed that mere assertiveness may have undesired consequences, for example, going out alone in the evening or freely interacting with male students and teachers may be seen as a voluntary exposure or provocation to sexual assault and harassment. Hence, in the absence of strong legal protection for the rights of women on campus, being less assertive and quiet appears to be a survival strategy in use by many women, in order not to bring attention to themselves. It is also noteworthy that in a context of repressive social relations, agents have diminished 'anticipatory dispositions' (McNay, 2008). As a result, disadvantaged individuals may have little or no hope for change, and their agency remains inhibited which, in turn, strengthens their condition of deprivation and misrecognition.

Clearly women's conformity to structures of disadvantage has a more serious implication for the reproduction of gender inequality in HE. Given the gender repression being perpetuated implicitly or explicitly in the form of prejudice and unfavourable working and learning environments, women's inability to question the structures of disadvantage can be an indicator of how HEIs reproduce and legitimatize gender relations in society rather than transform them. Lack of critical consciousness to the structures of gender-based deprivation and subordination also reinforces the 'pipeline problem' metaphor of policy actors. The 
pipeline argument (see Blickenstaff, 2005; Monroe \& Chiu, 2010) holds that the problem of gender inequality in HEIs in general and the absence of women in high level academic and management positions in particular is due to a lack of sufficiently qualified women which, in turn, is linked to the poor progress rate of female students in the lower level education, low cumulative grade point averages and their underrepresentation in the academic staff. As such gender inequality in professorial and senior management positions can only be improved with the passage of time, as more women come into the subsystem and the number of women in the admission and hiring pool increases. This analysis fails to take account of the systemic and structural factors which impede the progress of women in the academy. By attributing the problem to a past legacy, pipeline thinking obscures and delays appropriate policy intervention, including: transformative equity instruments that improve the pool of female school leavers eligible for HE; efforts to promote the participation and success of women across all fields of study (especially in science and technology disciplines); a career development program that prioritises women; and pro-active gender and equity awareness programs which reach all members of the university community.

\section{Conclusion}

In this paper, we have demonstrated that expressions of gender-based qualitative inequality in Ethiopian HE range from subtle unfavourable views of women's academic capacities to outright violence. The lived experiences of women affirm that neither a strict adherence to the meritocratic principles of admission policy nor a ratification of the right to nondiscrimination in access to education and a nominal advantage at entry point are sufficient in and of themselves to rectify socially constructed inequalities on the basis of gender, class, ethnic background or rurality. A focus on the quantitative dimensions of gender equity (mainly on increasing admission rates and recruiting more women members of faculty) is a superficial approach to the multi-dimensional problem of inequality. Beyond numerical increases, social justice in $\mathrm{HE}$ requires paying attention to the existing curricula representations, pedagogical practices and power relations within the institutions. For instance, the learning experiences - the subject/course content (curriculum) to be taught and the pedagogical arrangements in which staff and students engage - are crucial sites of cultural reproduction and transformation. They reflect academics' expectations and assumptions about 
gender roles; and play roles in maintaining or challenging the gender status-quo in society. How does the formal curriculum depict women and their roles: independent, brilliant scientist and problem solving; or dependent, loving and care-giving to their family; or both? Hence, it is necessary to make sure that women's roles and contributions are recognised and properly represented in the curricula, the learning processes are freed from stereotypes and misrepresentations, and viable support mechanisms are in place not only to raise female students' confidence and awareness but also to empower them to challenge the mistreatment and harassment they may face on campus.

It is timely and critical to ensure that the framing of gender inequality in $\mathrm{HE}$ as a policy problem does not exclude the qualitative dimensions of this problem, including women's constrained agency resulting from structural forces of deprivation, experiences of disrespect and misrecognition, and fear of coercion and violence. Addressing structural inequalities in HEIs requires a closer look at gendered experiences and power relations within the institutions. Without substantive, enabling equity instruments that address existing institutionalized gender practices, gender inequality persists (and will contintue), despite nominal gains in statistical terms.

\section{References}

Andualem, T., \& Gebre-Egziabher, A. (2009). Evaluation of affirmative action on women's higher education in Ethiopia (unpublished research report).

Arnot, M., \& Fennell, S. (2008). Gendered education and national development: Critical perspectives and new research. Compare: A Journal of Comparative and International Education, 38(5), 515-523.

Baron, R. A., \& Byrne, D. (2003). Social psychology (10 ${ }^{\text {th }}$ ed.). Boston, MA: Allyn \& Bacon.

Blickenstaff, J. C. (2005). Women and science careers: Leaky pipeline or gender filter? Gender and Education, 17(4), 369-386.

Bodenhausen, G. V., \& Richeson, J. A. (2010). Prejudice, stereotyping, and discrimination. In R. F. Baumeister \& E. J. Finkel (Eds.), Advanced social psychology (pp. 341-383). Oxford: Oxford University Press.

Bourdieu, P. (1990). In other words: Essays towards reflexive sociology. Cambridge: Polity Press.

Bourdieu, P. (2001). Masculine domination (R. Nice Trans). Stanford: Stanford University Press.

Brown, P. (2003). The Opportunity Trap: education and employment in a global economy. European Educational Research Journal, 2(1), 141-179. 
Connell, R. (2009). Gender: In world perspective ( ${ }^{\text {nd }}$ ed.). Cambridge: Polity.

Denzin, N. K. (1994). The art and politics of interpretation. In N. K. Denzin \& Y. S. Lincoln (Eds.), Handbook of qualitative research (pp.500-515). Thousand Oaks: Sage Publications.

Deutsch, F. (2007). Undoing Gender. Gender \& Society, 21(1), 106-127.

FDRE [Federal Democratic Republic of Ethiopia] (2009). Higher Education Proclamation, No.650/2009. Addis Ababa: Federal Negarit Gazeta.

Frye, M. (1983). The Politics of Reality. Trumansburg, NY: Crossing.

Giddens, A. (1984). The constitution of society. Cambridge: Polity Press.

Hesse-Biber, S. N. (2012). Feminist research: Exploring, interrogating, and transforming the interconnections of epistemology, methodology, and method. In S. N. Hesse-Biber (Ed.), Handbook of feminist research: Theory and praxis (pp.2-26). Los Angeles: Sage.

Kamberelis, G., \& Dimitriadis, G. (2008). Focus group discussion: Articulations of pedagogy, politics and inquiry. In N. Denzin \& Y. Lincoln (Eds.), Collecting and interpreting qualitative materials ( $3^{\text {rd }}$ ed.) (pp.545-561). Los Angeles: Sage.

Kimmel, M. S. (2008). The gendered society ( $3^{\text {rd }}$ ed.). New York: Oxford University Press.

Kincheloe, J. L., \& McLaren, P. L. (2008). Rethinking critical theory and qualitative research. In N. K. Denzin \& Y. S. Lincoln (Eds.), The landscape of qualitative research (pp.403455). Los Angeles: Sage Publications.

Krais, B. (1993). Gender and symbolic violence: Female oppression in the light of Pierre Bourdieu's social practice. In C. Calhoun, E. LiPuma \& M. Postone, (Eds.), Bourdieu: Critical perspectives (pp.156-177). Cambridge: Polity Press.

Levine, N. D. (1999). Greater Ethiopia: The evolution of multiethnic society (2 ${ }^{\text {nd }}$ ed.). Chicago: The University of Chicago Press.

Mama, A. (2003). Restore, reform but do not transform: The gender politics of higher education in Africa. Journal of Higher Education in Africa, 1(1), 101-125.

Mama, A., \& Barnes, T. (2007). Rethinking universities. Feminist Africa, 8(1), 1-7.

McNay, L. (2004). Agency and experience: Gender as a lived relation. The Sociological

Review, 52(2), 175-190. DOI: DOI: 10.1111/j.1467-954X.2005.00530.X

McNay, L. (2008). Against recognition. Cambridge: Polity Press.

Miller, K. L., \& Miller, S. M. (2002). A model for evaluating gender equity in academe. In J. Digeorio-Lutz (Ed.), Women in higher education: Empowering change (pp. 103-114). London: Praeger.

MoE [Ministry of Education]. (2004). Five-year Strategic Framework for Enhancing Women's Participation in Tertiary Education in Ethiopia. Addis Ababa: MoE.

MoE [Ministry of Education]. (2011). Education statistics annual abstract 2009/10, Addis Ababa: MoE.

MoE [Ministry of Education]. (2013). Education statistics annual abstract 2011/12, Addis Ababa: MoE.

Molla, T. (2013). Higher education policy reform in Ethiopia: The representation of the problem of gender inequality. Higher Education Policy, 26(2), 193-215; doi:10.1057/hep.2012.25 
Monroe, K. R., \& Chiu, W. F., (2010). Gender equality in the academy: The pipeline problem. PS: Political Sciences \& Politics, 43(2), 303-308.

Morley, L. (2006). Hidden transcripts: The micropolitics of gender in Commonwealth universities. Women's Studies International Forum, 29 (6), 543-551.

Morley, L. (2011). Sex, grades and power in higher education in Ghana and Tanzania. Cambridge Journal of Education, 41(1), 101-115.

Ridgeway, C. (2011). Framed by gender: How gender inequality persists in the modern world. Oxford: Oxford University Press.

Risman, B. J. (2004). Gender as a social structure: Theory wrestling with activism. Gender \& Society, 18(4): 429-450. DOI: 10.1177/0891243204265349

Sewell, W. H., (1992). A theory of structure: Duality, agency, and transformation. American Journal of Sociology, 98(1), 1-29.

Singh, J. (2002).Women and management in higher education: A good practice handbook. Paris: UNESCO.

TGE [Transitional Government of Ethiopia]. (1994). Education and training policy. Addis Ababa: St. George Printing Press.

Tilly, C. (1998). Durable inequality. Berkeley: University of California Press.

Young, I. M. (1990). Justice and the politics of difference. Princeton: Princeton University Press.

Young, I. M. (2000). Inclusion and democracy. Oxford: Oxford University Press.

Uggen, C., \& Blackstone, A. (2004). Sexual harassment as a gendered expression of power. American Sociological Review, 69(1), 64-92.

West, C., \& Fenstermaker, S. (1995). Doing difference. Gender \& Society, 9(1), 8-37.

West, C., \& Zimmerman, D. (1987). Doing gender. Gender \& Society, 1(2), 125-151.

West, C., \& Zimmerman, D. (2009). Accounting for Doing Gender. Gender \& Society, 23(1), 112-122.

Wondimu, H. (2003). Ethiopia. In D. Teferra \& P. Altbach (Eds.), African higher Education: An international reference handbook. Bloomington, Indiana: University of Indiana Press.

Worku, Y. (2001). Ethiopia: From bottom to top in higher education - gender role problems. International Journal of Sociology and Social Policy, 21(1\&2), 98 - 104.

UNESCO [United Nations Educational, Scientific and Cultural Organization]. (1988). Ethiopia - Higher education: Development of university education. Paris: Author.

Van Manen, M. (1997). Researching lived experience: Human science for an action sensitive pedagogy ( $2^{\text {nd }}$ ed.). London: Althouse Press. 